\section{DENTAL THERAPISTS CAN IMPROVE THE NATION'S HEALTH}

Dental therapists have a major part to play in getting the nation to adopt a healthier way of life, according to Fiona Sandom, president of the British Association of Therapists (BADT).

Fiona maintains that dental therapists are perfectly placed to champion the NHS programme of 'Making Every Contact Count'.

In a drive to get UK health professionals to change the lifestyle choices and behaviour of patients, the programme, launched in 2012, invites NHS frontline workers to engage patients in a 'healthy lifestyle chat'.

Fiona said: 'Effective health promotion and prevention of oral disease, including supporting general health improvement activities around diet and nutrition, are key parts of what dental therapists do. Day in day out, they deliver oral health care that's evidence based while offering education about the risks of alcohol and tobacco to patients, for example. As many of our members work closely with the public on a daily basis, they are in an excellent position to talk to people about their wellbeing and help them make healthy choices.'

As well as identifying oral problems, the education of patients about links between oral health and their overall health plays a large part in the care dental therapists are trained to provide.

The drive by the NHS Future Forum to 'make every contact count' was launched with the acknowledgement that 'there are millions of opportunities every day for the NHS to help to improve people's health and wellbeing and to reduce health inequalities, but to take this opportunity it needs a different view of how to use its contacts with the public. A routine dental check-up or eyetest, for example, is a chance to offer advice to help someone stop smoking?.

In recognition of dental therapists as health 'game changers', the BADT is this year rewarding qualifying dental therapy students with achievement awards in a bid to encourage excellence in prevention. Each dental therapy school will be invited to nominate a key student and the winners will be invited to join Fiona at her table at the presidential dinner taking place at the BADT annual conference on 25-26 September. www.badt.org.uk

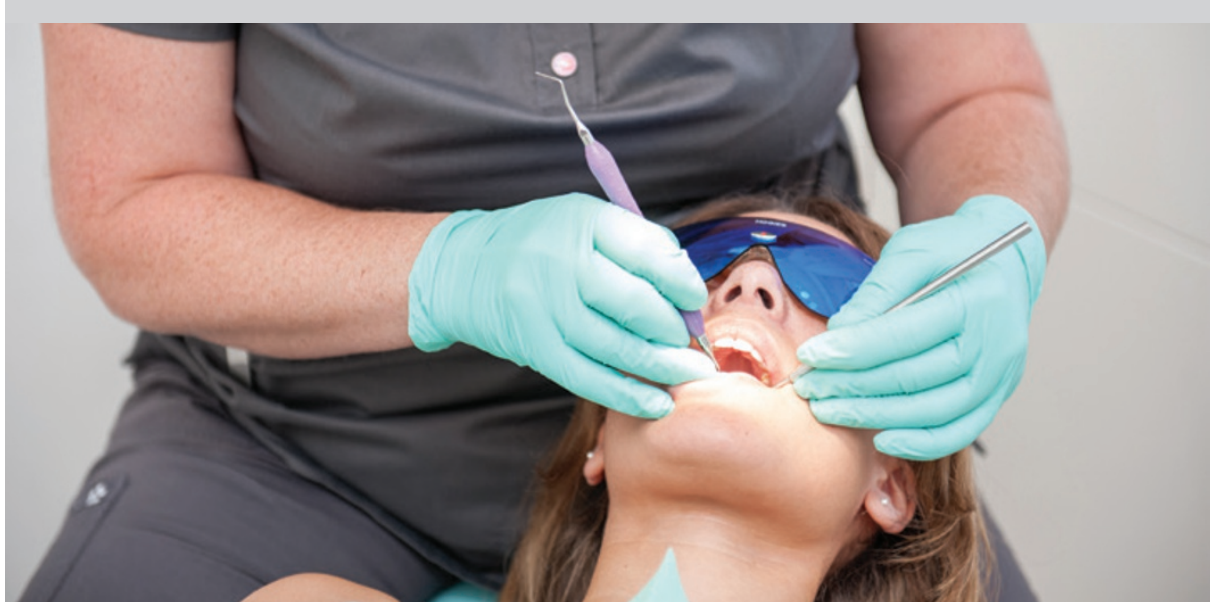

\section{$6^{\text {TH }}$ DCP SYMPOSIUM TO BE HELD IN CARDIFF}

The Dental Postgraduate Section of Cardiff University, in collaboration with The Royal College of Surgeons of Edinburgh, will be holding their 6th Dental Care Professionals (DCP) Symposium on Friday 8 May 2015 at the Marriott Hotel, Cardiff.

The theme of the symposium will be 'Practically perfect - in every way?' and will address the pressures of life in a front line dental practice. It will look at ways and means of alleviating these pressures using tools that will help DCPs prioritise, focus and use good management skills.

The day costs $£ 25$, including lunch and six hours of continuing professional development (CPD). To book, visit http://www.walesdeanery.org/index.php/en/dentistry.html using course code DCP/SYMP/15/KH and then call Kath Liddington to make a card payment. The closing date for applications is Friday 10 April 2015. For further information email liddingtonke@cf.ac.uk.
TRAINING ESSENTIALS: BUY ONE GET ONE FREE

This winter take advantage of the British

Dental Association (BDA) special event

offer and book any Training Essentials

course $^{\star}(£ 125$ for DCPs) and get one

Training Essentials course FREE to help

top up your CPD hours in 2015.

Courses available cover CORE CPD,

GDC recommended, and business and

personal development topics (Table 1).

Take a look at the full Training Essentials

event listing at www.bda.org/training

for details.

To book your event places call the

Events Team direct on 02075634590 .

Limited availability, so book today and don't miss out!

*This offer cannot be booked online

and cannot be applied to events

already booked or two day courses.

For full terms and conditions

www.boda.org/training

Table 1 Training Essentials

courses 2015

Course

Dates

(all Fridays and

all in London

unless other-

wise stated)

\begin{tabular}{l|l} 
Management of & $13 / 3 / 15$
\end{tabular}

medical emergencies $\quad 11 / 9 / 15$

Safeguarding

children and

vulnerable adults

$20 / 3 / 15$

Growing your practice 27/3/15

Leoring

(1)

$$
\text { (entan }
$$

1

I$$
\text { appr }
$$

Performance

appraisals

\begin{tabular}{l|l}
\hline An IRMER course in & \\
dental radiography & $13 / 3 / 15$ \\
and radiation & (Manchester) \\
protection & $5 / 6 / 15$
\end{tabular}

protection

Oral cancer

$5 / 6 / 15$

Online marketing and

social networking

Handling

complaints$$
\text { Inte }
$$$$
\text { 列 }
$$$$
\text { I }
$$

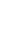

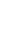

